\title{
Economics
}

2021; 10(3): 79-86

$\mathrm{http}: / /$ www.sciencepublishinggroup.com/j/eco

doi: $10.11648 /$ j.eco.20211003.12

ISSN: 2376-659X (Print); ISSN: 2376-6603 (Online)

\section{On the Country of Origin Effect of Eco-Label}

\section{Yingjun Xu}

Research Center for Food Safety and Green Agricultural Development, Qufu Normal University, Rizhao, China

Email address:

xuyingjun@qfnu.edu.cn

\section{To cite this article:}

Yingjun Xu. On the Country of Origin Effect of Eco-Label. Economics. Vol. 10, No. 3, 2021, pp. 79-86. doi: 10.11648/j.eco.20211003.12

Received: July 4, 2021; Accepted: July 13, 2021; Published: July 27, 2021

\begin{abstract}
With the rapid development of global industrialization and urbanization, the ecological problems is increasingly aggravating. The consumers' demand for safety and environment friendly food is increasing. Taking organic tomato as an example, we design the choice experiment to acquire 847 consumers' relevant data from Shandong province, and use the random parameters logit model to investigate the consumers' preferences for organic labels from different countries (or districts). The results show that consumers have the highest willing to pay for EU organic label, the Chinese Hong Kong organic label, the Brazil organic label and the China organic label are behind successively. The influence of the ecological consciousness on the consumer preference is small. In general, consumers' preference orders for organic labels from different countries (or districts) are the same for all ecological consciousness groups. The willingness to pay of the consumers in the low ecological consciousness group and the middle ecological consciousness group are very close, while the willingness to pay of the consumers in the high ecological consciousness group is slightly higher than that of the consumers in the low and middle ecological consciousness group. Food safety risk consciousness has significant effect on the consumer preference, and the larger differences exist between the organic labels which are from different countries. The character in effect of country of origin and its way of changing, maybe not only as the important basis of certificating service choice and target market positioning strategy of food provider, but also hope to have reference value for Chinese certification system reform and the development of certification food market.
\end{abstract}

Keywords: Tomato, Organic Label, Willingness-to-Pay, Choice Experiment, Random Parameters Logit Model

\section{Introduction}

With the rapid development of global industrialization and urbanization, the ecological problems such as environmental degradation and biodiversity loss is increasingly aggravating [1-2]. The consumers' demand for safety and environment friendly food is increasing [3-4], which lead to the available of eco labeling products. Eco label is a kind of product label which based on the valuation on the influence on environment [5]. Pollution free food label, green food label, organic food label, low carbon seal, and environmental label are the current most important eco labels [6]. Study on the willing to pay for different eco labeled food becoming an important research field. Organic label which with the characteristic of diverse certification body and diverse identification form is more and more popular among consumers and is stricter than pollution free food label and green food label [7]. Chen et al. constructed a consuming behavior model which can be used to study the consumers' preference for traditional food, pollution free food, green food and organic food and has studied consumers' willingness to pay for organic food [8]. Yin et al. explored consumers' willingness to pay for organic label and traceable information label of shrimp and found that the more knowledge the higher willingness to pay [9]. Zhou et al. explored urban consumers' willingness to pay for pork with low-carbon label and the influencing factor and found that consumers' willingness to pay premium for pork with low-carbon label was 3.95 RMB [10]. Wang et al. studied the urban consumers' willingness to pay for the quality safety attributes of pork such as green food label, brand label, food additive information label, and animal welfare label and found that the willingness to pay for green food label was the biggest [11].

The original meaning of country of origin is the country which made the product. The researchers called the influences of information that which country did the product make in on consumers' valuation, attitude, and purchase intention as country of origin effect which is affected by a variety of factors [12]. The theory of country of origin effect is based on several 
theories such as signal theory, stereotypes theory, and network stakeholders theory [13]. In the 1960s, Schooler noticed the country of origin effect issue and did the empirical research [14] From then on the period of sporadic research last more than ten years. After 1980s, related research mushroomed and country of origin effect became a common phenomenon. In the early $21^{\text {st }}$ century Chinese researchers began their studies on country of origin effect, from then on, the phenomenon that country of origin as an important information clue which can affect consumers' valuation on food or service triggered extensive academic interest [15] and the attention of policy makers [16]. Researchers began to study the country of origin issue, and investigated the effect of "made in" which as a product's valuation clue on consumers' purchase decision making [17]. Zhang et al. found that the products' country of origin image have positive effect on consumers' perception valuation, which has significant positive correlation with their purchase intention [18]. Wang et al. did a systemic organizing of related papers on country of origin from several aspects such as the concepts' evolvement, mechanism of action, antecedent variables, intermediary variables, and consequence variables and constructed an country of origin model which can be used to do further research [19]. Using Becher-DeGroot-Marschak auction mechanism to collect the consumers' preference data, and through multinomial logit model to deal with the data, Yin et al. researched the consumers' country of origin effect on the certification labels of tomato, and found that major consumers preferred organic labels from developed countries [20]. There were also some paper studied how to impair the country of origin effect from the perspectives of the amount of information provided and the appearance of the information [21-22].

Though there were several researchers began to focus on consumers' preferences on different ecological labels [23], to the best of our knowledge, few studies exist regarding ecological label's country of origin effect. Ecological label belongs to certification service product, therefore comparing to other products there is significant differences exist in the perspectives of characteristics and valuation mechanism, so it is hard for studies exist on country of origin effect to explain related phenomenon in certification service field [17]. Then, is there country of origin effect exists in ecological label certification service? If the answer is yes, so what are the factors that will affect country of origin? Exploring the answers to all the questions has important guidance sense to how to establish and improve China's ecological certification system and certification regulatory policy and to the suppliers' making of objective market strategically, which is the purpose of research of this paper.

\section{Theoretical Framework and Econometric Model}

China is a major country about the production and consumption of vegetable, with the production volume of vegetable of 703.176 million tons in $2019^{*}$. Among all the vegetables, tomato is the most popular one. In the early 1990 s, China became the largest producer of tomato followed by the United States. The production of tomato of China is 61.632 million tons, which with an increase of 2036 thousands of tons compare to $2017^{\dagger}$. So, we choose tomato as the research object Based on the random utility theory [24], tomato can be thought of as the organism of organic label attribute and price attribute. Assume that individual consumers are rational, so they will choose the tomato product plan which can give them the biggest utility. Therefore, the tomato product plan that give consumer the biggest utility has the biggest probability to be chosen by the consumer. We may represent the utility $U_{n i}$ that consumer $n$ can attain from tomato product $i$ as follows:

$$
\begin{gathered}
U_{n i}=V_{n i}+\varepsilon_{n i} \\
V_{n i}=X_{n i}^{\prime} \beta
\end{gathered}
$$

$V_{n i}$ is the deterministic part of the utility, and $\varepsilon_{n i}$ is the error term, which shows that the consumer's real utility is unobservable from the researchers' perspective. From the consumer's perspective, the choosing process is the process maximizing the utility, which is to choose the product plan which give them the biggest utility. If consumer $n$ chose the tomato plan $i$ from choice set $C$, which means consumer $n$ attain the biggest utility from tomato plan $i$ among choice set $C$. Then the probability consumer will choose tomato plan $i$ from choice set $C$ is as follows:

$$
\begin{gathered}
P_{n i}=\operatorname{prob}\left(U_{n i}>U_{n j} ; j=1, \ldots, J ; j \neq i\right) \\
P_{n i}=\operatorname{prob}\left(\varepsilon_{n i}-\varepsilon_{n j}>U_{n j}-U_{n i} ; j=1, \ldots, J ; j \neq i\right)
\end{gathered}
$$

If we assume $\varepsilon_{n i}(i=1, \ldots, J)$ is extreme value distribution of type I independently, then the probability consumer $n$ will choose product plan $i$ can be simplified as follows [25]:

$$
P_{n i}=\frac{e^{X_{i}^{\prime} \beta}}{\sum_{j=1}^{J} e^{X_{j}^{\prime} \beta}}, \quad i=1, \ldots, J
$$

This is multinomial logit model which assume consumer preferences are homogeneous that is not real sometimes. A more rational assumption which is more line with the actual situation is consumer preferences are heterogeneous. In this assumption, $\beta$ is not a constant, but a random variable and with a certain distribution, therefore the utility consumer $i$ attain from product plan $m$ in choice situation $t$ can be represented as follows [26]:

\footnotetext{
* Analysis on the production of vegetable, the movements of vegetable price, cost of vegetable and import and export of vegetable of China in 2019. [EB/OL]. http://www.chyxx.com/industry/202005/858935.html. (2020-05-06) [2021-05-30] $\dagger$ Analysis on the production of tomato sauce industry in China and enterprise's $\begin{array}{llll}\text { current operation } & 2019 \\ \text { [EB/OL] }\end{array}$ http://www.chyxx.com/industry/202009/894355.html. (2020-09-10) [2021-05-30]
} 


$$
U_{i m t}=\beta_{i}^{\prime} X_{i m t}+e_{i m t}
$$

In equation (6) $X_{i m t}$ is the vector comprises of variables related to product plan and decision maker which are observable, and $\beta_{i}$ is the coefficient vector which represents consumer preference, and $e_{i m t}$ is the random error term. Therefore consumer's utility can be represented as follows:

$$
U_{i m t}=\left(\beta+\Omega^{\prime} \eta_{i}\right)^{\prime} X_{i m t}+e_{i m t}
$$

In equation (7), $\beta$ is a vector of mean value, $\Omega^{\prime} \eta_{i}$ is the heterogeneous deviation, $\Omega$ is the cholesky matrix measuring the correlation of the random effects. We can assume the random deviation $\eta_{i}$ follow any rational distribution. If the value of $\beta_{i}$ is known, the probability that consumer $i$ will choose product plan $j$ is the logit probability. But in equation (7), the coefficient $\beta_{i}$ is random and is unknown, therefore the unconditional choice probability is the integral of logit probability on the density of $\beta_{i}$ as is shown in equation (8).

$$
P_{i m t}=\int\left(\frac{e^{\beta^{\prime} X_{i m t}}}{\sum_{j} e^{\beta^{\prime} X_{i j t}}}\right) f(\beta) d \beta
$$

Equation (8) is the general form of MNL called rand parameters logit model (RPL) and $f(\beta)$ is multiple probability density function. Assume consumer make choices at $T$ moments, among which the chosen product plans series is $I=\left\{i_{1}, \ldots, i_{T}\right\}$, then the probability that consumer chose it is as follows:

$$
L_{i T}(\beta)=\prod_{t=1}^{T}\left[\frac{e^{\beta_{i}^{\prime} X_{i i_{t} t}}}{\sum_{t=1}^{T} e^{\beta_{i}^{\prime} X_{i t_{t} t}}}\right]
$$

The unstrained probability is the integral on the distribution of $\beta$ :

$$
P_{i T}=\int L_{i T}(\beta) f(\beta) d \beta
$$

An important assumption of MNL is independence of irrelevant alternatives (IIA), however, the assumption of consumer preferences are heterogeneous which relax the limit of IIA is more in line with reality. Therefore, the RPL which is the updated version of MNL is more suit to do the consumer preferences research, so in this paper we will investigate the consumer willing to pay for different organic labels using RPL.

\section{Experiment Design and Data Source}

\subsection{Choice Experiment Design}

The purpose of this study is to examine whether there is country or origin effect on ecological label, so we focus on the consumer willingness to pay for organic label. Therefore we assume the tomato product plan comprises of organic label and price. The organic label attribute is designed to include five levels includes European organic label (EUORG), Brazil organic label (BRORG), Hong Kong organic label (HKORG), Chinese organic label (CNORG) and no organic label. The reason for designing attributes and levels such way is as follows. We choose European organic label as representative of organic label from developed countries or region. Based on the important status of Brazil in the world agricultural and China's trade pattern, we choose Brazil organic label as the representative of organic label from developing countries. Chinese Hong Kong is a developed region, which has different food safety certification policy than Chinese mainland, so our choosing to investigate its food safety certification policy has important reference value. For the price attribute, we design three levels which is high (4.5 yuan per $500 \mathrm{~g}$ ), medium (3.5 yuan per $500 \mathrm{~g}$ ) and low (2.5 yuan per $500 \mathrm{~g}$ ) based on real price in the market and Yin et al.'s research [27] which is shown in table 1.

Table 1. Attributes and levels in choice experiment.

\begin{tabular}{ll}
\hline Attribute & Levels \\
\hline \multirow{2}{*}{ Organic label } & European organic label (EUORG), Brazil organic label (BRORG), Hong Kong organic label (HKORG), Chinese organic label \\
Price & (CNORG), No organic label (NOORG) \\
\hline
\end{tabular}

Based on the levels of the designed attributes in table 1, we can attain fifteen virtual tomato product. We let each choice tusk includes two virtual tomato product and one "Opt Out" option. If we use full factor design, then the respondents have to complete 225 choice tusks, which is not realistic. So this paper use the fractional factorial design to generate the choice tusk in order that reducing the choice task number under the premise that ensure the efficiency. We use the SAS software to generate three versions each has fifteen choice tasks.

\subsection{Survey Areas and Sample Description}

The survey area is chosen at Shandong province. There are significant differences in the development levels of the eastern coastal area and western inland areas of Shandong province, which may be seen as the microcosm of the significant differences of the development level of the eastern coast area and middle and western inland areas of China. Therefore, choosing the Shandong province as the survey area may be a good choice. The author choose three cities in the eastern (Qingdao, Weihai and Rizhao) and middle (Jinan, Zibo, and 
Taian) and western (Liaocheng, Heze and Dezhou) of Shandong province respectively to conduct the survey. The specific survey site is chosen as local supermarket and the farmer's market, the reason of such choice lies in that supermarket and the farmer's market is the major place urban residents purchasing vegetables [28].

The survey is conducted through interview by chosen undergraduate and graduate students. To enhance the randomness of sample, we chose the third consumer coming into view as the respondent [29]. The survey is conducted at February 2021, in which the respondent first completes the choice experiment and then structured questionnaire. The questionnaire includes the demographic characteristics of the respondents, cognitive for the organic label, ecological consciousness, food safety risk awareness and et al. Referencing to the method of Ortega (2011) [30], the ecological consciousness (EC) and food safety risk consciousness (FSRC) is measured by level 7 semantic difference scale. In total, there are 916 respondents complete the survey and we attain the valid questionnaires of 847 . There are $56.55 \%$ of respondents are female and the $43.55 \%$ are male, which is basically in line with the current situation that the female is the major food purchaser in China. The sample description statistics result is shown in Table 2.

Table 2. Consumers' demographic variable and basic description.

\begin{tabular}{|c|c|c|c|c|c|c|c|}
\hline Variable & $\begin{array}{l}\text { Classification } \\
\text { Indexes }\end{array}$ & $\begin{array}{l}\text { Sample } \\
\text { Number }\end{array}$ & Percent (\%) & Variable & Classification Indexes & $\begin{array}{l}\text { Sample } \\
\text { Number }\end{array}$ & Percent $(\%)$ \\
\hline \multirow{4}{*}{ Age } & Under 30 & 126 & 14.88 & \multirow{3}{*}{ Education } & Primary school and under & 256 & 30.22 \\
\hline & $30-45$ & 268 & 31.64 & & Middle school & 335 & 39.55 \\
\hline & $45-60$ & 289 & 34.12 & & Post-graduate and above & 256 & 30.22 \\
\hline & $60-$ & 164 & 19.36 & \multirow{3}{*}{$\begin{array}{l}\text { Family income } \\
\text { per year } \\
\text {-- }\end{array}$} & Less than 60000 China Yuan & 563 & 66.47 \\
\hline \multirow{2}{*}{ Sex } & Male & 368 & 43.45 & & More than 60000 China Yuan & 284 & 33.53 \\
\hline & Female & 479 & 56.55 & & & & \\
\hline
\end{tabular}

\section{Model Estimation Results}

\subsection{Estimation Results of RPL}

Effect coding is used in this paper and we first assume the parameters of value of variable that is price and exiting variable that is Opt Out are fix, then the parameters of all the levels of related attributes is normally distributed [31]. The RPL model estimation results using NLOGIT 5.0 software is shown in Table 3.

Table 3. Model estimation results of RPL.

\begin{tabular}{|c|c|c|c|c|}
\hline Variable & Parameter & Stand deviation & T Value & 95\% Confidence Interval \\
\hline \multicolumn{5}{|l|}{ Main effect } \\
\hline PRICE & $-0.1314 * * *$ & 0.03 & -4.12 & {$[-0.19,-0.07]$} \\
\hline Opt Out & $-1.4152 * * *$ & 0.16 & -9.05 & {$[-1.71,-1.10]$} \\
\hline EUORG & $0.5357 * * *$ & 0.03 & 17.62 & {$[0.46,0.58]$} \\
\hline HKORG & $0.3690 * * *$ & 0.06 & 5.56 & {$[0.24,0.49]$} \\
\hline BRORG & $0.3321 * * *$ & 0.03 & 11.42 & {$[0.27,0.38]$} \\
\hline \multicolumn{5}{|l|}{ Intersection term } \\
\hline $\mathrm{EC} \times \mathrm{EUORG}$ & $0.5642 * * *$ & 0.03 & 18.34 & {$[0.49,0.62]$} \\
\hline $\mathrm{EC} \times \mathrm{HKORG}$ & $0.4613 * * *$ & 0.09 & 4.90 & {$[0.27,0.64]$} \\
\hline $\mathrm{EC} \times \mathrm{BRORG}$ & $0.3625^{* * *}$ & 0.07 & 5.55 & {$[0.24,0.49]$} \\
\hline $\mathrm{EC} \times \mathrm{CNORG}$ & 0.39 & 0.26 & 1.50 & {$[-0.12,0.89]$} \\
\hline FSRC $\times$ EUORG & $0.4609 * * *$ & 0.05 & 8.45 & {$[0.35,0.56]$} \\
\hline $\mathrm{FSRC} \times \mathrm{HKORG}$ & $0.4123 * * *$ & 0.05 & 7.98 & {$[0.30,0.49]$} \\
\hline $\mathrm{FSRC} \times \mathrm{CNORG}$ & $-0.2387 * * *$ & 0.06 & -3.67 & {$[-0.35,-0.11]$} \\
\hline \multicolumn{5}{|c|}{ Diagonal values of Cholesky matrix } \\
\hline STDEV (EUORG) & $0.1490 * * *$ & 0.02 & 8.35 & {$[0.11,0.17]$} \\
\hline STDEV (HKORG) & $0.2338 * * *$ & 0.06 & 3.56 & {$[0.10,0.35]$} \\
\hline STDEV (BRORG) & $0.1551^{* * *}$ & 0.06 & 2.43 & {$[0.03,0.27]$} \\
\hline STDEV (CNORG) & $0.1286^{* *}$ & 0.06 & 2.07 & {$[0.01,0.24]$} \\
\hline Log Likelihood & -2058.92 & McFadden $\mathrm{R}^{2}$ & 0.27 & -- \\
\hline AIC & 4149.80 & -- & -- & -- \\
\hline
\end{tabular}

Note: $* * *, * * *$ denote significant at $10 \%, 5 \%, 1 \%$ level respectively; NOORG is the reference group of label attribute.

We can see from the model estimation results of Table 3 that EUORG has the biggest part worth and followed by HKORG,
BRORG, and CNORG in turn. That is consumer like EUORG most, then is the HKORG, the last is BRORG and CNORG. 
From the parameters of the intersection term between the EC and each organic label wen can include that the part worth that consumer attained from EUORG, HKORG, and BRORG increases with the increase of their ecological awareness and all is significant at the $1 \%$ level. But as far as China is concerned, the effect is not significant. From the parameters of the intersection terms between the FSRC and each organic label we can include that consumers can gain more part worth from URORG and HKORG, while less part worth from BRORG and CNORG with the increase of FSRC.

\subsection{WTP Estimation Results}

Based on the estimation results of Table 3 and the ordinal utility character of main effect, the formula (11) be used to calculate the consumers' willingness to pay [32].

$$
W T P_{k}=-2 \times\left(\frac{\beta_{k}+\sum_{j} \beta_{k \times j}}{\beta_{\text {price }}}\right)
$$

In formula (11), $W T P_{k}$ denotes the willingness to pay for the $k$ th level of one certain attribute, and $\beta_{k}$ denotes corresponding parameter. $\beta_{k \times j}$ denotes the parameter of the intersection between the $k$ th level of one attribute and a certain level of another attribute and $\beta_{\text {price }}$ is the parameter of variable price. Because the effect code is used, the number 2 is need in formula (11) [33]. Parametric bootstrapping technique is used to get the estimated confident interval of willingness to pay [34]. Table 4 shows the results of the mean of willingness to pay and its confidence interval.

Table 4. Consumer willingness to pay and confidence interval.

\begin{tabular}{llll}
\hline Level of attribute & WTP [95\% confidence interval] & Level of attribute & WTP [95\%confidence interval] \\
\hline EUORG & $3.93[3.08,4.89]$ & BRORG & $1.95[1.40,2.59]$ \\
HKORG & $2.72[1.97,3.57]$ & CNORG & $1.63[0.94,2.45]$ \\
\hline
\end{tabular}

The estimation results of consumer willingness to pay for different organic label showed in Table 4 tell us that consumer has the biggest willingness to pay for EUORG, then is HKORG, the last is BRORG and CNORG. The order of size of consumer willingness to pay is in line with the order of size of part worth in Table 3. Consumer preferred EUORG which is from developed countries, which is consistent with the results of Cai and He (2012) which found that compared to products from developing countries, consumer like more for products from developed countries [35]. Consumer willingness to pay for HKORG is slight low than EUORG, and is far more than |BRORG and CNORG. As one developed special administrative region of China, Hong Kong' food safety management system is relatively strict and HKORG gain the consumers' recognition. Consumer willingness to pay for BRORG is slightly bigger than that of CNORG, the possible reason of which lies in that such certification fraud rumor as the "pseudo organic event in wine industry" weakened consumer trust for domestic organic certification.

\subsection{Consumer Ecological Awareness and Willingness to Pay}

The survey results of consumer ecological awareness show that the lowest and highest score of respondents ecological awareness are 2 and 7, respectively, with the mean is 4.2 score. There is 44.5 percent respondent whose self-evaluation score is above 5. The respondents is divided into three groups according to their ecological awareness score, that is low ecological awareness group whose score is between 1 and 3, middle ecological awareness group whose score is between 4 and 5, and the high ecological awareness group whose score is between 6 and 7. The willingness to pay for different organic label of consumer belonging to different ecological awareness group calculated through parametric bootstrapping technique is shown in Table 5.

Table 5. Ecological awareness and consumer willingness to pay.

\begin{tabular}{|c|c|c|c|c|}
\hline Consumer category & Attribute level & mean & Stand error & Confidence interval $95 \%$ \\
\hline \multirow{4}{*}{ Low ecological awareness group $(1 \leq \mathrm{EC} \leq 3)$} & EUORG & $3.7150 * * *$ & 0.21 & {$[3.29,5.76]$} \\
\hline & HKORG & $2.6122 * * *$ & 0.31 & {$[2.00,4.65]$} \\
\hline & BRORG & $2.3349 * * *$ & 0.29 & {$[1.75,4.37]$} \\
\hline & CNORG & $1.5082 * * *$ & 0.43 & {$[0.65,3.55]$} \\
\hline \multirow{3}{*}{ Middle ecological awareness group $(4 \leq \mathrm{EC} \leq 5)$} & EUORG & $3.9371 * * *$ & 0.37 & {$[3.20,5.98]$} \\
\hline & HKORG & $2.8228 * * *$ & 0.48 & {$[1.87,4.87]$} \\
\hline & BRORG & $2.4953 * * *$ & 0.42 & {$[1.67,4.54]$} \\
\hline \multirow{4}{*}{ High ecological awareness group $(6 \leq \mathrm{EC} \leq 7)$} & EUORG & $4.3430 * * *$ & 0.36 & {$[3.63,6.39]$} \\
\hline & HKORG & $3.4187 * * *$ & 0.48 & {$[2.47,5.46]$} \\
\hline & BRORG & $2.9804 * * *$ & 0.33 & {$[2.34,5.03]$} \\
\hline & CNORG & $2.1530 * * *$ & 0.25 & {$[1.66,4.21]$} \\
\hline
\end{tabular}

Notes: $* * *, * * *$ denotes significant at $10 \%, 5 \%, 1 \%$ level respectively.

Estimation results in Table 5 show that consumers in different ecological awareness group has the same preference order for organic labels come from different countries, in which EUORG ranks first, then is HKORG, the last is BRORG and CNORG. With the increase of ecological awareness, consumer willingness to pay for different organic 
label all have slight advance. The consumer willingness to pay increment when from the middle ecological awareness group to the high ecological awareness group is bigger than that from low ecological awareness group to the middle ecological awareness group. In a word, consumer ecological awareness has small effect on their willingness to pay for various organic labels. The possible reasons are manifold. Firstly, though the ecological awareness of the public is increasing, their willingness to pay for ecological compensation is not enough yet. Most consumers are willing to pay premium to buy organic food mainly as a rational choice to safeguard their health from the food safety perceptive and not ecological consumption from the ecological compensation' point of view. Secondly, in this paper, the data on ecological awareness is gained through the self-subjective judgment, which has the tendency of overestimating relevant data, which leads the possibility that there is a little deviation between the surveyed data and the consumers' real attitude.

\subsection{Consumer Food Safety Risk Awareness and Willingness to Pay}

The survey results about consumer food safety risk awareness show shat the mean of FSRC mean is 4.85 , the standard deviation is 1.26 , and more than half of the consumer has the score bigger than 5 . The participants are divided into three groups based on their food safety risk awareness score, which is low risk awareness group, middle risk awareness group and the high risk awareness group. Willingness to pay for organic labels from different countries of different risk awareness group calculated through parametric bootstrapping technique is shown in Table 6.

Table 6. Consumer willingness to pay of different food safety risk awareness group.

\begin{tabular}{|c|c|c|c|c|}
\hline Consumer type & Attribute level & mean & Stand deviation & $95 \%$ confidence interval \\
\hline \multirow{4}{*}{ Low risk awareness group $(1 \leq \mathrm{FSRC} \leq 3)$} & EUORG & $3.6244 * * *$ & 0.48 & {$[2.68,4.72]$} \\
\hline & HKORG & $2.5512 * * *$ & 0.28 & {$[1.99,3.26]$} \\
\hline & BRORG & $2.2345 * * *$ & 0.32 & {$[1.59,3.02]$} \\
\hline & CNORG & $1.5614 * * *$ & 0.27 & {$[1.03,2.25]$} \\
\hline \multirow{3}{*}{ Middle risk awareness group $(4 \leq \mathrm{FSRC} \leq 5)$} & EUORG & $4.2517 * * *$ & 0.40 & {$[3.46,5.19]$} \\
\hline & HKORG & $3.2886 * * *$ & 0.32 & {$[2.64,4.07]$} \\
\hline & BRORG & $2.9716^{* * *}$ & 0.30 & {$[2.37,3.71]$} \\
\hline \multirow{4}{*}{ High risk awareness group $(6 \leq \mathrm{FSRC} \leq 7)$} & EUORG & $4.4841 * * *$ & 0.39 & {$[3.70,5.40]$} \\
\hline & HKORG & $3.5296 * * *$ & 0.28 & {$[2.97,4.23]$} \\
\hline & BRORG & $3.0704 * *$ & 0.31 & {$[2.45,3.84]$} \\
\hline & CNORG & $2.1524 * * *$ & 0.35 & {$[1.47,2.99]$} \\
\hline
\end{tabular}

Note: $*, * *, * * *$ denotes significant at $10 \%, 5 \%, 1 \%$ level, respectively.

We can learn from Table 6 that consumer willingness to pay for different organic label improve in general with the increase of consumer food safety risk awareness. This is in line with the research conclusion that consumer food safety risk awareness affects their willingness to pay for safe food significantly conducted by Yeung and Morris [36]. The relationship between consumer willingness to pay for organic label from different countries and the FSRC is complicated. From the low risk awareness group to the middle risk awareness group, consumer willingness to pay for four different organic labels improved greatly. From middle risk awareness group to high risk awareness group, the change of consumer willingness to pay varies significantly. Consumer willingness to pay for EUORG and HKORG improved greatly, and for BRORG the increment is small, while in terms of CNORG, consumer willingness to pay decrease a little. In general, the increment of consumer willingness to pay from middle risk awareness group to high risk awareness group is small than the increment from the low risk awareness group to the middle risk awareness group, and the increment of willingness to pay for organic label from different countries varies significantly. The possible reason lies in that those consumers who has the very high food safety risk awareness has very low confidence for the food safety system, which has significantly affect their confidence and willingness to pay for organic label specially for domestic organic labels. Furthmore, affected by the "false organic Maotai wine" event and other food safety event, many consumes begin to doubt the authority of CNORG, so they don't want to pay further more price.

\section{Conclusion}

From the consumer preference perspective view, through choice experiment and RPL model, this paper investigated the country of origin effect for organic label, and analyzed the effect of ecological awareness and food safety risk awareness on consumer preference, then drew some conclusions.

Firstly, consumer willingness to pay for organic labels from different countries varies significantly, which for EUORG is the biggest, followed by HKORG, BRORG and CNORG. The discovery that consumer preferred labels from developed countries (regions) verified the existence of country of origin in certification service field of ecological labels.

Secondly, Consumer ecological awareness has no significant effect on their willingness to pay for various organic labels. The preference order for organic labels from different countries of different groups divided based their ecological awareness level. The increment of consumer willingness to pay for different organic labels from the low ecological awareness group to the middle ecological 
awareness group is small, while the increment from the middle ecological awareness to the high ecological awareness group is big. From the model estimation results we can conclude that though Chinese consumer ecological awareness level has improved, their willingness to pay based on ecological compensation is still small.

Thirdly, with the increment of consumer food safety risk awareness, whose willingness to pay for various organic labels increase accordingly. The growth of consumer willingness to pay from the middle risk awareness group to the high risk awareness group is less than that from the low risk awareness group to the middle risk awareness, and the way it changes varies in organic labels from different countries of origin. The character in effect of country of origin and its way of changing, maybe not only as the important basis of certificating service choice and target market positioning strategy of food provider, but also hope to have reference value for Chinese certification system reform and the development of certification food market.

\section{Acknowledgements}

The author gratefully acknowledges the financial support of this research through the project 18BJY153, supported by Social Science Foundation of China.

\section{References}

[1] Yin S J, Gao Y, Wu L H. Constructing social governance system for food safety with Chinese characteristics [M]. People's Publishing House, 2017.

[2] Zhu L L, Guo P F. Evaluation game theory and simulation analysis of agricultural product quality and safety supervision. Statistics \& Decision, 2018 (20): 54-58.

[3] Louriro, M. L., Mccluskey, J. J., Mitelhammer, C. Will consumers pay a premium for eco-labeled apples? The Journal of Consumer Affairs, 2002, 36 (2): 203-219.

[4] Qi W E, Lin C. The influencing factors on consumers purchase intention of fresh products [J]. Journal of South China Agricultural University (Social Science Edition), 2018, 17 (1): 78-93.

[5] Mcckysjet, J. J., Loureiro, M. L. Consumer preferences and willingness to pay for food labeling: a discussion of empirical studies. Journal of Food Distribution Research, 2003, 34 (3): 95-102.

[6] Xuan Y N. Research trends and prospects of consumer preferences for ecologically labeled food [J]. Consumer Economics, 2004 (5): 59-61.

[7] Yin S J, LI R, Wu L H, Chen X J. China food safety development report [M]. Peking university press, 2018.

[8] Chen Y S, Qiao J, Li B L. Empirical study on influence factors of consumers' purchase intention of certificated food [J]. Finance and Trade Research, 2011 (3): 121-128.

[9] Yin, S. J., Han, F., Chen, M., Li, K., Li, Q. Chinese urban consumers' preference for white shrimp: Interactions between organic labels and traceable information. Aquaculture, 2020, 521 (15): 1-11.
[10] Zhou Y H, Wu L F. Study on willingness to pay for low-carbon agricultural products of urban consumers-Taking low-carbon pork as an example [J]. Journal of Agrotechnical Economics, 2012 (8): 4-12.

[11] Wang W Z, Wu L P. Analysis on willingness to pay for pork's quality and safety attribute of urban residents-Based on choice experiments [J]. Journal of Agrotechnical Economics, 2013 (11): 24-31.

[12] Roth, M., Romeo, J. B. Matching product category and country image perceptions: A framework for managing country-of-origin effects. Journal of International Business Studies, 1992, 23 (3): 477-497.

[13] Liu J L, Raymond L. A literature review on the country-of-origin effect research [J]. Journal of Business Economics, 2018 (6): 61-73.

[14] Schooler, R. D. Product bias in Central American common market. Journal of Marketing Research, 1965 (2): 394-397.

[15] Huang H S. A review of researches on country-of-origin effect [J]. Advances in Psychological Science, 2003, 11 (6): 692-699.

[16] Zhou Z M, He H P, Liu Y N. The formation mechanism of Chinese national-Brand consciousness perspective of national brand community [J]. China Soft Science, 2010 (5): $45-56$

[17] Zhang H, Wang T, Liu H S. Does the country of origin effect also exist in serve products? A study on the country of origin for service products and its influence on consumer service evaluation [J]. Finance \& Trade Economics, 2011 (12): 127-133.

[18] Zhang X, Xu B, Peng J S. The effects of country-of- origin and corporate image on purchase intention [J]. Finance and Trade Research, 2013 (6): 123-132.

[19] Wang T, Nie C Y, Liu Y W, Meng J J. A scientometric analysis of country-of-origin research [J]. Journal of Marketing Science, 2017 (2): 71-94.

[20] Yin S J, Wang X N, Chen Y S. Does certification logo exist country-of-origin effect? The case study of organic tomatoes [J]. Statistics \& Information Forum, 2015, 30 (8): 99-105.

[21] Wang T, Zhang Q, Zhang H, Zhou L, Liu H S. Reducing the country-of-origin effects: The presentation of products information activates the analytic process [J]. Acta Psychologica Sinica, 2012, 44 (6): 841-852.

[22] Zhang Q, Wang T, Gong Y P. Can brand and price really counter country-of-origin effects: Different distribution of attribute weight [J]. Acta Psychologica Sinica, 2013, 45 (12): 1381-1392.

[23] Janssen, M., Hanm, U. Product labeling in the market for organic food: consumer preferences and willingness-to-pay for different organic certification logos. Food Quality and Preference, 2012, 25 (1): 9-22.

[24] Lancaster, K. J. A new approach to consumer theory. The Journal of Political Economy, 1966, 74 (2): 132-157.

[25] James, J. S., Rickard, B. J., Rossman, W. J. Product differentiation and market segmentation in applesauce: using a choice experiment to assess the value of organic, local, and nutrition attributes. Agricultural and Resource Economics Review, 2009, 38 (3): 357-370. 
[26] McFadden, D., Train, K. Mixed mnl models for discrete response. Journal of Applied Econometrics, 2000, 15 (5): 447-470.

[27] Yin S J, Xu Y J, Chen Y S. How do food quality information label affect consumers preferences: Based on the choice experiment of 843 samples in Shandong province [J]. China Rural Survey, 2015 (1): 39-49+94.

[28] Yang Z H, Zhai Y L. Analysis on the circulation cost of agricultural product supply chain in supermarket: Proof from Shenyang vegetable market [J]. Issues in Agricultural Economy, 2011 (2): 73-78+112.

[29] Wu, L. H., Xu, L. L., Zhu, D., Wang, X. L. Factors affecting consumer willingness to pay for certified traceable food in Jiangsu province of China. Canadian Journal of Agricultural Economics, 2012, 60 (3): 317-333.

[30] Oritega, D. L., Wang, H. H., Wu, L., Olynk, N. J. Modeling heterogeneity in consumer preferences for select food safety attributes in China. Food Policy, 2011, 36 (2): 318-324.

[31] Lusk, J. L., Roosen, J., Fox, J. Demand for beef from cattle administered growth hormones or fed genetically modified corn: a comparison of consumers in France, Germany, the
United Kingdom, and the United States. American Journal of Agricultural Economics, 2003, 85 (1): 16-29.

[32] Lim, K. H., Hu, W. Y., Maynard, L. J., et al. U. S. consumers' preference and willingness to pay for country-of-origin-labeled beef steak and food safety enhancements. Canadian Journal of Agricultural Economics, 2013, 61 (1): 93-118.

[33] Bech, M., Gyre-hansen, D. Effects coding in discrete choice experiments. Health Economics, 2005, 14 (10): 1079-1084.

[34] Krinsky, I., Robb, A. L. On approximating the statistical properties of elasticities. The Review of Economics and Statistics, 1986, 68 (4): 715-719.

[35] Cai Y Y, He J X. Pleasure and peace: An empirical study of the effects of positive emotions on country of origin effects [J]. Journal of Marketing Science, 2012, 8 (3): 76-87.

[36] Yeung, R. M. W., Morris, J. Food safety risk consumer perception and purchase behaviour. British Food Journal, 2001, 103 (3): 170-186. 